\title{
Rationale and design of study
} of dapagliflozin versus sitagliptin treatment efficacy on prevention of cardiovascular risk factors in type 2 diabetes patients: the DIVERSITY-CVR study

\author{
Fumika Shigiyama, Naoki Kumashiro* ${ }^{*}$, Ayako Fuchigami and Takahisa Hirose
}

\begin{abstract}
Background: Recent studies reported that sodium glucose cotransporter 2 (SGLT2) inhibitors reduced the cardiovascular morbidity and mortality in patients with type 2 diabetes mellitus (T2DM) compared to placebo in contrast to no reduction with dipeptidyl peptidase 4 (DPP4) inhibitors. However, there are no comparative studies on the effects of SGLT2 inhibitors and DPP4 inhibitors on HbA1c, body weight and hypoglycemia as risk factors of cardiovascular diseases. The aim of the present ongoing study is to compare the effects of dapagliflozin, a SGLT2 inhibitor, with those of sitagliptin, a DPP4 inhibitor, on cardiovascular risk factors in T2DM patients with inadequate glycemic control.

Methods: The study of dapagliflozin versus sitagliptin treatment efficacy on prevention of cardiovascular risk factors in T2DM patients (DIVERSITY-CVR study) is a prospective, randomized, open-label, blinded-endpoint, parallel-group, comparative study. A total of 340 T2DM patients treated with metformin alone or with no glucose-lowering agents (hemoglobin $\mathrm{A} 1 \mathrm{c} \geq 7.0$ and $<10.0 \%$ ) will be randomized into the dapagliflozin group ( $5-10 \mathrm{mg} /$ day, $n=170$ ) and the sitagliptin group (50-100 mg/day, $\mathrm{n}=170$ ), and treated for 24 weeks. The primary endpoint is the rate of achieving a composite endpoint of the following three items at 24th week; (1) HbA1c $<7.0 \%$; (2) body weight loss of $\geq 3.0 \%$ from baseline; (3) avoidance of hypoglycemia. Hypoglycemia will be monitored using the flash glucose monitoring system. The secondary outcomes include each component of the primary endpoint, plus indices of lipid metabolism, and evaluations related to safety.
\end{abstract}

Conclusions: There is lack of solid information on differences in the therapeutic effects of SGLT2 inhibitors and DPP4 inhibitors on multiple risk factors for cardiovascular diseases. It is anticipated that the results of the DIVERSITY-CVR study provides useful clinical data on the management of patients with T2DM, including reducing the risk of CVD. The results of this study will become available in 2019.

Trial registration University Hospital Medical Information Network Clinical Trial Registry (UMIN000028014). Registered 30 June 2017

Keywords: Dapagliflozin, Sitagliptin, Cardiovascular diseases, Type 2 diabetes

*Correspondence: naoki.kumashiro@med.toho-u.ac.jp

Division of Diabetes, Metabolism, and Endocrinology, Department

of Medicine, Toho University Graduate School of Medicine, 6-11-1

Omori-Nishi, Ota-ku, Tokyo 143-8541, Japan 


\section{Background}

Type 2 diabetes mellitus (T2DM) is a high risk factor for cardiovascular diseases (CVD) [1-4], and a major cause of mortality worldwide [5]. Hyperglycemia can cause abnormal tissue function and lead to endothelial dysfunction, plaque formation, structural alteration of arterial tissue and atherosclerosis [6-9]. Previous studies reported that $1 \%$ reduction in hemoglobin A1c (HbA1c) concentration was associated with significant reductions in diabetes-related deaths (21\%) and myocardial infarction (14\%) [10]. However, severe hypoglycemia in patients with T2DM is also known to have negative effects on the incidence of CVD and mortality risk [11-13]. Previous meta-analysis study of 903,510 patients with T2DM reported that the odds ratio for CVD due to severe hypoglycemia was 2.05-fold [13]. Obesity is another risk factor for CVD [14-16], and is a well-established risk factor for T2DM [17]. Obesity causes ectopic fat accumulation and this leads to insulin resistance [18]. Insulin resistance is one of the major pathogenic factor of T2DM and progression of CVD [19]. Thus, the management of T2DM patients should focus on lowering blood glucose and body weight without hypoglycemia.

Regarding the choice of treatment, various oral glucose-lowering agents of different mechanisms are available. Sodium glucose cotransporter 2 (SGLT2) inhibitors, can prevent elevation of blood glucose levels by suppression of the reuptake of sodium and glucose from primitive urine [20]. In addition to glucose-lowering effects, empagliflozin and canagliflozin, two SGLT2 inhibitors, have been demonstrated on their protective role on cardiovascular events among patients with T2DM [21-23]. In addition, Dapagliflozin Effect on CardiovascuLAR Events [DECLARE TIMI-58]; NCT01730534, which examines the effect of dapagliflozin, another SGLT2 inhibitor used in this study, on cardiovascular outcome, has been ongoing and the result will be available soon [24]. In this regard, we have demonstrated that dapagliflozin can correct endothelial dysfunction compared to metformin in T2DM with moderate hyperglycemia [25]. In contrast to SGLT2 inhibitors, few randomized clinical trials have shown the beneficial effects of dipeptidyl peptidase 4 (DPP4) inhibitors on cardiovascular events in patients with T2DM compared to placebo control [23, 26-28]. However, sitagliptin, a DPP4 inhibitor, was shown to lower the rate of newly diagnosed CVD in T2DM [29] and we also demonstrated that linagliptin, another DPP4 inhibitor, improved endothelial function, as assessed by flow-mediated dilation in patients with T2DM [30].

To date, there are few prospective randomized clinical trials that have compared the efficacy of SGLT2 inhibitors and DPP4 inhibitors regarding the prevention of
CVD risks, such as hyperglycemia, body weight gain and severe hypoglycemia. Therefore, we planned and partly executed this clinical trial aimed to compare the therapeutic benefits of dapagliflozin and sitagliptin on CVD risks, with special focus on HbA1c, body weight and hypoglycemia. Hypoglycemia will be monitored by the flash glucose monitoring system (FGM) (FreeStyle Libre Pro; Abbott Diabetes Care, Tokyo, Japan), which continuously records subcutaneous interstitial glucose concentrations for 14 days without the need for re-calibration and has been used for the assessment of hypoglycemia [31]. The comparative study of treatment efficacy of dapagliflozin versus sitagliptin in reducing cardiovascular risk factors in T2DM patients: DIVERSITY-CVR study will provide better understanding of the effects of dapagliflozin and sitagliptin to establish an effective treatment strategy for T2DM and prevention of CVD.

\section{Methods}

Study design

The DIVERSITY-CVR study is an ongoing, prospective, randomized open-label, blinded-endpoint study, registered on the University Hospital Medical Information Network Clinical Trial Registry (UMIN000028014), a non-profit organization in Japan that meets the requirements of the International Committee of Medical Journal Editors (ICMJE). This study was approved by the Medical Ethics Committee of Toho University (approval \#M17024). The study will be conducted according to the Declaration of Helsinki and current legal regulations in Japan. To avoid bias regarding the processes of enrollment, randomization, data collection and management are conducted by a third party.

\section{Study population}

In this study, the target number of patients required for registration was set at 340 Japanese patients with T2DM who regularly visited the Outpatient Clinics of 62 institutions across Japan (listed in the Additional file 1). Recruitment for the study began in July 2017 and will end in June 2018. At the time of writing this report, a total of three subjects have completed the 24-week study, 178 subjects have been recruited and started the study, and 132 subjects are to be recruited during the remaining part of the study. The inclusion criteria were set as follows: (1) T2DM patients who have not used any glucose-lowering agents within 8 weeks before consenting, or those who have only used metformin (250-2250 mg/day), in addition to diet and exercise; (2) HbA1c (NGSP values) level of $7.1 \%$ or higher but no more than $10.0 \%$; (3) males or females aged 20-80 years; (4) patients with body mass index (BMI) of $23 \mathrm{~kg} / \mathrm{m}^{2}$ or higher; (5) patients who can be monitored closely for medication compliance; (6) 
patients who provide written informed consent. The following exclusion criteria are also used: (1) patients with type 1 diabetes or secondary diabetes; (2) patients with medical history of diabetic ketoacidosis; (3) patients with medical history of myocardial infarction, cerebral infarction, or stroke within 12 weeks before consent to the study; (4) patients with severe liver disease; (5) patients with renal disease [serum creatinine $1.3 \mathrm{mg} / \mathrm{dL}$ or higher, or estimated glomerular filtration rate (eGFR) less than $45 \mathrm{~mL} / \mathrm{min} / 1.73 \mathrm{~m}^{2}$ ]; (6) patients with unstable hypertension or dyslipidemia within 12 weeks before consent to the study; (7) pregnant or breastfeeding patients, or those planning to become pregnant during the study; (8) dehydrated patients [test results show abnormality in hematocrit or blood urea nitrogen (BUN) or complaint of dehydration].

\section{Randomization and study intervention}

Enrollment, randomization and follow-up schedule are outlined in Fig. 1. After consent and enrollment, the eligible subjects are randomly assigned at equal numbers into the dapagliflozin group (dapagliflozin 5-10 mg/ day), and sitagliptin group (sitagliptin $50-100 \mathrm{mg}$ /day). The randomization is conducted by a computer-based dynamic allocation method using $\mathrm{HbAlc}$ and BMI values collected at consent as the background factor for allocation. After enrolment, patients are asked to refrain from changing the dose of concomitant drugs or use additional medications during the 24-week study, such as other glucose-lowering agents, anti-hypertensive agents, lipid-lowering agents or antiplatelet agents. During the 8-week screening period, all baseline measurements of blood and urine samples and FreeStyle Libre Pro (Abbott Diabetes Care, Tokyo) (measurements of more than 5 days) are performed within 8 weeks after obtaining patients' consent and before the allocation and administration of the study drug. After baseline data collection, patients of the dapagliflozin group are administered dapagliflozin $5 \mathrm{mg} /$ day, which will be increased to $10 \mathrm{mg} /$ day if HbA1c was $7.0 \%$ or higher after the 8 weeks. On the other hand, patients of the sitagliptin group are treated with sitagliptin $50 \mathrm{mg} /$ day, which will be increased to $100 \mathrm{mg} /$ day from 8 weeks if necessary to achieve the target HbA1c of $<7.0 \%$. The treatment intervention start date is set as the observation start date. The assigned treatment is continued for 24 weeks (duration of the study).

\section{Study outcomes}

The primary study endpoint is the rate of achieving a composite endpoint of the following three items from baseline to the 24th week; (1) HbA1c below 7.0\%; (2) body weight loss of $3 \%$ relative to baseline; (3) avoidance of hypoglycemia $[<3.0 \mathrm{mmol} / \mathrm{L}(<54 \mathrm{mg} / \mathrm{dL})]$. The secondary endpoints include the following items at 24 weeks: (1) rate of achieving HbA1c at $<7.0 \%$; (2) rate of achieving body weight loss of $\geq 3 \%$ relative to baseline; (3) rate of avoiding hypoglycemia; (4) changes in HbA1c, fasting plasma glucose (FPG), body weight and $\mathrm{BMI}$ relative to baseline; (5) changes in lipid metabolism indices relative to baseline: triglyceride, total cholesterol, high-density lipoprotein (HDL) cholesterol and low-density lipoprotein (LDL) cholesterol; (6) changes in the levels of blood insulin, serum uric acid, BUN, serum creatinine, eGFR, aspartate aminotransferase (AST), alanine aminotransferase (ALT), serum sodium $(\mathrm{Na})$, serum potassium $(\mathrm{K})$, serum chloride $(\mathrm{Cl})$ and blood cell count; (7) circadian change in glucose measured by FGM; (8) day-to-day variability in glucose by FGM; (9) frequency and duration of hypoglycemia; (10) medication adherence rate.

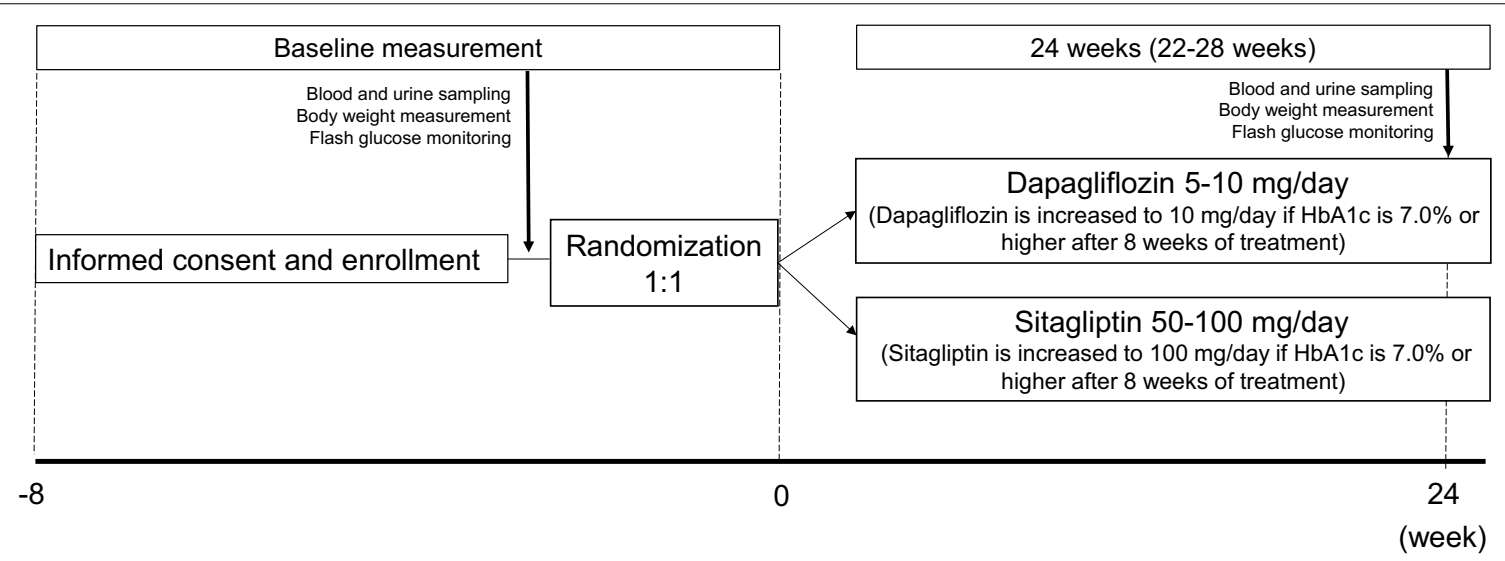

Fig. 1 Patient recruitment process 


\section{Observation items and schedule}

Clinical and biochemical data are collected at baseline and after the 24-week treatment period. Body weight is measured at hospital/clinic. All subjects wear the same disposable examination robe during body weight measurement. All blood samples for analyses are obtained after overnight fasting. The following items are measured using blood/urine samples; HbA1c, FPG, serum insulin, triglyceride, total cholesterol, HDL cholesterol, uric acid, BUN, creatinine, eGFR, AST, ALT, $\mathrm{Na}, \mathrm{K}, \mathrm{Cl}$ and blood cell count. LDL cholesterol is computed from the obtained data. In addition, to monitor the incidence of hypoglycemia, all subjects will wear the FGM (Freestyle Libre Pro; Abbott Diabetes Care, Tokyo) for 14 days at baseline and 24-week. In brief, the Freestyle Libre Pro device is attached on the upper arm of the subject, then glucose data are stored on the sensor every $15 \mathrm{~min}$. Both the subjects and investigators are blinded to the glucose data during the study. After the 14-day glucose measurement, the subjects take off the sensor by themselves and send it to the data management third-party who is also blinded to the clinical information. The data management third-party downloads the glucose data from the sensor to the device software (Abbott Diabetes Care Inc.). All subjects are asked to record their daily intake of their medication using handy medication diary. Physicians check the record at subject's every visit, and this record will continue through the study period and finally medication rate will be calculated using this record.

\section{Safety and evaluation of adverse events}

During the course of the study, the investigators constantly monitor any adverse events (AEs) through regular medical checkups. Once an AE occurs, regardless of the presence or absence of a causal relationship with the study drug, the investigator reports the details immediately to the respective institution, the principal investigator and the administration office. All related AEs, not only side effects to the drug but also abnormal values from the clinical tests, are to be reported and documented.

\section{Sample size estimation}

To our knowledge, there is no study that evaluated SGLT2 inhibitor on a composite endpoint (HbA1c below $7.0 \%$, body weight loss of $3 \%$, avoidance of hypoglycemia) as the primary outcome. Our previous study; the Relief study [30] and DEFENCE study [25], were used to select of rates of the above achievements for each group, and determine the required sample size for this study. In the Relief study [30], we referenced that $10.0 \%$ of patients that used a DPP-4 inhibitor, had HbA1c of 7.1\% or higher and BMI of $23 \mathrm{~kg} / \mathrm{m}^{2}$ or higher at baseline, could achieve the composite endpoint at 16 weeks. In the DEFENCE study [25], the proportion of subjects who used SGLT2 inhibitors and achieved the composite endpoint was $40.0 \%$ at 16 weeks. We estimated the achievement rates to be 25 and $40 \%$ for our sitagliptin and dapagliflozin groups, respectively. Based on these assumptions, the estimated sample size required to detect a significant difference in Chi square test between the two groups under the conditions of significance level of $5 \%$ on both sides and a power of $80 \%$, was 152 cases per group. Assuming a dropout rate of $10 \%$, the target number of enrolled patients was set at 170 cases per group for a total of 340 cases for the two groups.

\section{Statistical analysis}

Analyses for the primary and secondary endpoints will be primarily performed on the full analysis set (FAS). FAS includes research subjects who are enrolled in this study and assigned to a study treatment, however, subjects without data for the primary endpoint or subjects with a significant study protocol violation are excluded. Safety analysis with adverse events is performed on the treated set. Summary statistics are calculated for continuous variables. For comparisons of the two groups, the Chi square test or Fisher's exact test is used for nominal variables, and two sample $t$ test or Wilcoxon ranked-sum test is used for continuous variables. For analysis of the primary endpoint, i.e., the proportion of participants who will be able to achieve all of the following: (1) HbA1c below 7.0\% at 24th week, (2) body weight loss of $\geq 3 \%$ from baseline at 24th week, (3) no hypoglycemia $[<3.0 \mathrm{mmol} / \mathrm{L}$ $(<54 \mathrm{mg} / \mathrm{dL})$ ] throughout the study, comparison between the groups is performed using the Chi square test. For the secondary endpoint, the measured values and the extent of changes or percent changes, summary statistics are used on one-sample $t$ test for comparisons within each group, and on two-sample $t$ test for comparisons between groups. If the data deviate greatly from normal distribution, the Wilcoxon signed-rank test is used within each group, and Wilcoxon rank sum test is performed for comparisons between groups. All statistical analyses are to be performed independently by the administrative office of the DIVERSITY-CVR study using SAS software version 9.4 (SAS Institute, Cary, NC).

\section{Human rights and ethical principles of study subjects}

All investigators involved in this study comply with the "World Medical Association Declaration of Helsinki" (2013 revision), and "Ethical Guidelines for Medical and Health Research Involving Human Subjects" (December 22, 2014, Ministry of Education, Culture, Sports, Science and Technology/Ministry of Health, Labor and Welfare), and other bylaws and regulations. 


\section{Discussion}

The DIVERSITY-CVR study is designed to compare the preventive effects of dapagliflozin and sitagliptin on CVD in T2DM patients. The rate of achieving a composite endpoint of the following three items at 24 weeks will be assessed as the primary endpoint; (1) HbA1c below 7.0\%; (2) body weight loss of $3 \%$ from baseline; (3) avoidance of hypoglycemia $[<3.0 \mathrm{mmol} / \mathrm{L}(<54 \mathrm{mg} / \mathrm{dL})]$.

Several large prospective randomized trials on the cardiovascular outcomes have been performed but only few showed a significant effect for strict glycemic control on reduction of cardiovascular mortality, with the exception of the UK Prospective Diabetes Study (UKPDS) 34 on newly diagnosed obese T2DM patients [32-35]. Subanalysis of the Action to Control Cardiovascular Risk in Diabetes (ACCORD) study showed that participants who had experienced symptomatic severe hypoglycemia were at greater risk of death than those who had experienced no hypoglycemia [36]. Another meta-analysis reported that strict blood glucose control was associated with adverse events of $2.5 \mathrm{~kg}$ weight gain and nearly doubled severe hypoglycemic episodes compared with standard treatment [37]. Taken together, these data suggest that glycemic control with severe hypoglycemic episodes and/ or weight gain may lead to increased risk of CVD, and thus, we focused on the achievement of glycemic control without hypoglycemia and weight gain.

SGLT2 inhibitors are relatively new oral glucoselowering agents and have attracted attention due to the recently reported improved cardiovascular outcomes in the large randomized controlled trials [21, 22]. In contrast, DPP4 inhibitors were reported neutral on cardiovascular outcomes in similarly large randomized controlled trials [26-28]. However, the mechanisms of improved cardiovascular outcomes by SGLT2 inhibitors are unclear, and the reason of difference on cardiovascular outcomes between SGLT2 inhibitors and DPP4 inhibitors is not well-addressed. Although we previously examined the effects of SGLT2 and DPP4 inhibition on endothelial function using flow-mediated dilation in T2DM patients treated with $750 \mathrm{mg}$ metformin [25, 30], we could not compare the effects of SGLT2 and DPP4 inhibition directly and both agents tended to increase the flow-mediated dilation.

The present study compares the effects of dapagliflozin and sitagliptin on cardiovascular risk factors, focusing on achievement of HbA1c below 7.0\%, 3\% loss of body weight, and avoidance of hypoglycemia. Composite endpoints are being used frequently as outcomes, even as primary endpoint [38], for clinical trials in T2DM [3941]. In addition, they have been adopted in a wide variety of clinical area especially CVD [39, 42, 43]. Unnikrishnan et al. [40] reviewed that composite endpoints have been preferred to assess the clinical benefit of intervention avoiding misinterpretation associated with competing risks factor bias and challenge of using a single outcome to validate the study objective in trials on patients with diabetes. The achievement of $\mathrm{HbA} 1 \mathrm{c}$ below $7.0 \%$ is set as one of the components of the primary endpoint based on the following studies. The Diabetes Control and Complications trial study in type 1 diabetic patients showed significant reduction of microvascular complications in the intensive treatment group with HbA1c controlled to $7.1 \%$ [44]. The Kumamoto study also reported that prevention of the onset and progression of diabetic microangiopathy can be achieved by keeping $\mathrm{HbA} 1 \mathrm{c}$ at $<6.9 \%$, fasting blood glucose concentration at $<110 \mathrm{mg} / \mathrm{dL}$ and $2-\mathrm{h}$ post-prandial blood glucose concentration at $<180 \mathrm{mg} /$ dL [45]. In "Standards of Medical Care in Diabetes" of the American Diabetes Association, the target HbA1c for T2DM is set at around 7.0\% [46]. Thus, the previous large clinical trials also evaluated the rate of achievement of HbA1c below 7.0\% [27, 47, 48].

Another component of the primary endpoint is $3 \%$ loss in body weight. The Diabetes Prevention Program study demonstrated that body weight decrease of $1 \mathrm{~kg}$ contributed to $16 \%$ reduction in risk of diabetes [49]. Furthermore, post hoc analysis of the Look AHEAD randomized clinical trial demonstrated the effects of weight loss on CVD in overweight and obese T2DM with high risk for CVD [50]. Another previous study also reported that modest weight loss of $5-10 \%$ were associated with significant improvements in CVD risk factors at 1 year [51]. Thus, more than $5 \%$ loss of total body weight is recommended for overweight or obese people with T2DM in "Standards of Medical Care in Diabetes" of the American Diabetes Association as it can improve glycemic control, reduce the need for diabetes medications, and improve cardiovascular risk factors [52]. However, achieving this level of weight loss requires intense interventions, including energy restriction, regular physical activity, and frequent contact with health professionals [53]. In addition, $3 \%$ weight reduction is reported as the minimum requirement to improve health hazards at least in obese and overweight Japanese people [54]. Indeed, our previous studies showed body weight reduction of $2.8 \pm 1.9 \%$ and $0.0 \pm 2.8 \%$ relative to baseline in 16 weeks by dapagliflozin and linagliptin, respectively $[25,30]$. Therefore, we set $3 \%$ loss in body weight as a component of the primary endpoint in the present study.

In addition to reduction in $\mathrm{HbA} 1 \mathrm{c}$ and body weight loss, hypoglycemia is set as a component of primary endpoint. In the Action in Diabetes and Vascular Disease: Preterax and Diamicron Modified Release Controlled Evaluation (ADVANCE) study, severe hypoglycemia was clearly associated with increased 
risk of macrovascular events and death from cardiovascular cause [11]. It was also reported that hypoglycemia might cause CVD or death through abnormal cardiac arrhythmias [55], sympathoadrenal activation [56], inflammation [56], autonomic-failure [57], and impaired cardiac autoimmune function [58]. Recently, the International Hypoglycemia Study Group reported that blood glucose concentration of $<3.0 \mathrm{mmol} / \mathrm{L}$ $(<54 \mathrm{mg} / \mathrm{dL})$ is considered to be clinically significant biochemical hypoglycemia and recommended to be included in reports of clinical trials of glucose-lowering drugs [59].

While we expect to compare the effects of dapagliflozin and sitagliptin on cardiovascular risk factors, such as glycemic control, body weight loss, and hypoglycemia, this study will have several limitations. First, as this is an open-label treatment and subjects can also know the detail of the medications used. Second, all patients will be Japanese and the duration of study is short. Therefore, additional long-term trials of larger sample size that preferably include subjects of different ethnicities, are desirable. Third, there are no patients who are treated with insulin in this study. We aimed to compare the effect of DPP4 inhibitor and SGLT2 inhibitor on the improvement of cardiovascular risks in T2DM with metformin or drug naive. This study may indicate the potential of each medication as a choice for first or second line treatment. However, the effect of add-on therapy to insulin remains to be studied.

In conclusion, the DIVERSITY-CVR study is planned to demonstrate the differential efficacy of dapagliflozin compared to sitagliptin on cardiovascular risk factors, such as glycemic control, body weight and hypoglycemia, in patients with T2DM. There are no studies that assessed such cardiovascular risk factors as a composite primary endpoint. Notably, the subjects of this studies are treated with only metformin or no glucose lowering agents before enrolment, thus the results may support strict treatment at the early stage of diabetes. The results of this study may have a large impact on the treatment of T2DM, taking into consideration the cardiovascular complications. The results of this study will become available in 2019 .

\section{Additional file}

Additional file 1. List of 62 medical institutions participating in the study.

\section{Abbreviations}

CVD: cardiovascular diseases; DPP-4: dipeptidyl peptidase 4; FGM: flash glucose monitoring system; FMD: flow-mediated dilation; SGLT2: sodium glucose cotransporter 2; T2DM: type 2 diabetes mellitus.
Authors' contributions

FS, NK, AF and TH conducted the study, reviewed the manuscript and contributed to the discussion. FS and NK wrote and edited the manuscript. NK is the guarantor of this work and, as such, had full access to all study data and takes responsibility for the integrity of the data and the accuracy of data analysis. All authors read and approved the final manuscript.

\section{Acknowledgements \\ We thank 61 institutions across Japan (listed in the Additional file 1) for their participation to this study.}

\section{Competing interests}

N. Kumashiro received lecture fees from Novo Nordisk Inc, Takeda Pharmaceutical Company Limited, and Sanofi-Aventis Deutschland GmbH. THirose received research funds from AstraZeneca, Boehringer Ingelheim Pharmaceuticals, Inc., Ono Pharmaceutical Co., Ltd., Novo Nordisk Inc, Sanofi-Aventis Deutschland GmbH, Daiichi-Sankyo Co., Ltd., Eli Lilly Japan K.K., Takeda Pharmaceutical Company Limited, Mitsubishi Tanabe Pharma Corporation, Dainippon Sumitomo Pharma Co., Ltd., and Kissei Pharmaceutical Co., Ltd., and received lecture fee from Sanofi-Aventis Deutschland GmbH, Eli Lilly Japan K.K., Novo Nordisk Inc, Takeda Pharmaceutical Company Limited, Daiichi-Sankyo Co., Ltd., Mitsubishi Tanabe Pharma Corporation, Merck \& Co., Inc, Dainippon Sumitomo Pharma Co., Ltd., Novartis Pharma K.K., Kissei Pharmaceutical Co., Ltd., Boehringer Ingelheim Pharmaceuticals, Inc., Ono Pharmaceutical Co., Ltd., and AstraZeneca. All funding agencies had no role in study design, data collection and analysis, decision to publish, or preparation of the manuscript.

\section{Availability of data and materials}

The data analyzed during this study are available from the corresponding author of this article upon reasonable request.

\section{Consent for publication \\ Not applicable.}

\section{Ethics approval and consent to participate}

The study was approved by the Medical Ethics Committee of Toho University (approval \#M17024) and was conducted according to the Declaration of Helsinki and current legal regulations in Japan. All patients provided written informed consent before participation.

\section{Funding}

This study is supported by Astrazeneca Japan K.K.; the manufacturer of dapagliflozin. Astrazeneca Japan K.K. had no role in study design, data collection and analysis, decision to publish, or preparation of the manuscript.

\section{Publisher's Note}

Springer Nature remains neutral with regard to jurisdictional claims in published maps and institutional affiliations.

Received: 26 April 2018 Accepted: 6 June 2018

Published online: 12 June 2018

References

1. Moss SE, Klein R, Klein BE. Cause-specific mortality in a population-based study of diabetes. Am J Public Health. 1991;81:1158-62.

2. Haffner SM, Lehto S, Ronnemaa T, Pyorala K, Laakso M. Mortality from coronary heart disease in subjects with type 2 diabetes and in nondiabetic subjects with and without prior myocardial infarction. N Engl J Med. 1998:339:229-34

3. Fox CS, Coady S, Sorlie PD, Levy D, Meigs JB, D'Agostino RB Sr, Wilson PW, Savage PJ. Trends in cardiovascular complications of diabetes. JAMA. 2004;292:2495-9.

4. Tancredi M, Rosengren A, Svensson AM, Kosiborod M, Pivodic A, Gudbjornsdottir S, Wedel H, Clements M, Dahlqvist S, Lind M. Excess mortality among persons with type 2 diabetes. N Engl J Med. 2015;373:1720-32.

5. World Health Organization. The top 10 causes of death, fact sheet. http:// www.who.int/mediacentre/factsheets/fs310/en/. Accessed 24 May 2018. 
6. Feener EP, King GL. Vascular dysfunction in diabetes mellitus. Lancet. 1997;350(Suppl 1):SI9-13.

7. Vlassara H. Recent progress in advanced glycation end products and diabetic complications. Diabetes. 1997;46(Suppl 2):S19-25.

8. Sheetz MJ, King GL. Molecular understanding of hyperglycemia's adverse effects for diabetic complications. JAMA. 2002;288:2579-88.

9. Selvin E, Marinopoulos S, Berkenblit G, Rami T, Brancati FL, Powe NR, Golden SH. Meta-analysis: glycosylated hemoglobin and cardiovascular disease in diabetes mellitus. Ann Intern Med. 2004:141:421-31.

10. Stratton IM, Adler Al, Neil HA, Matthews DR, Manley SE, Cull CA, Hadden D, Turner RC, Holman RR. Association of glycaemia with macrovascular and microvascular complications of type 2 diabetes (UKPDS 35): prospective observational study. BMJ. 2000;321:405-12.

11. Zoungas S, Patel A, Chalmers J, de Galan BE, Li Q, Billot L, Woodward M, Ninomiya T, Neal B, MacMahon S, Grobbee DE, Kengne AP, Marre M, Heller S, ADVANCE Collaborative Group. Severe hypoglycemia and risks of vascular events and death. N Engl I Med. 2010;363:1410-8.

12. Duckworth WC, Abraira C, Moritz TE, Davis SN, Emanuele N, Goldman S, Hayward R, Huang GD, Marks JB, Reaven PD, Reda DJ, Warren SR, Zieve FJ, Investigators of the VADT. The duration of diabetes affects the response to intensive glucose control in type 2 subjects: the VA Diabetes Trial. J Diabetes Complications. 2011;25:355-61.

13. Goto A, Arah OA, Goto M, Terauchi Y, Noda M. Severe hypoglycaemia and cardiovascular disease: systematic review and meta-analysis with bias analysis. BMJ. 2013;347:44533.

14. Chen Y, Copeland WK, Vedanthan R, Grant E, Lee JE, Gu D, Gupta PC, Ramadas K, Inoue M, Tsugane S, Tamakoshi A, Gao YT, Yuan JM, Shu XO, Ozasa K, Tsuji I, Kakizaki M, Tanaka H, Nishino Y, Chen CJ, Wang R, Yoo KY, Ahn YO, Ahsan H, Pan WH, Chen CS, Pednekar MS, Sauvaget C, Sasazuki S, Yang G, Koh WP, Xiang YB, Ohishi W, Watanabe T, Sugawara Y, Matsuo K, You SL, Park SK, Kim DH, Parvez F, Chuang SY, Ge W, Rolland B, McLerran D, Sinha R, Thornquist M, Kang D, Feng Z, Boffetta P, Zheng W, He J, Potter JD. Association between body mass index and cardiovascular disease mortality in east Asians and south Asians: pooled analysis of prospective data from the Asia Cohort Consortium. BMJ. 2013;347:f5446.

15. Ndumele CE, Matsushita K, Lazo M, Bello N, Blumenthal RS, Gerstenblith G, Nambi V, Ballantyne CM, Solomon SD, Selvin E, Folsom AR, Coresh J. Obesity and subtypes of incident cardiovascular disease. J Am Heart Assoc. 2016;5:e003921.

16. Khan SS, Ning H, Wilkins JT, Allen N, Carnethon M, Berry JD, Sweis RN, Lloyd-Jones DM. Association of body mass index with lifetime risk of cardiovascular disease and compression of morbidity. JAMA Cardiol. 2018:3:280-7.

17. Vazquez G, Duval S, Jacobs JDR, Silventoinen K. Comparison of body mass index, waist circumference, and waist/hip ratio in predicting incident diabetes: a meta-analysis. Epidemiol Rev. 2007;29:115-28.

18. Shulman Gl. Ectopic fat in insulin resistance, dyslipidemia, and cardiometabolic disease. N Engl J Med. 2014;371:1131-41.

19. Laakso M, Kuusisto J. Insulin resistance and hyperglycaemia in cardiovascular disease development. Nat Rev Endocrinol. 2014;10:293.

20. Kalra S. Sodium glucose co-transporter-2 (SGLT2) inhibitors: a review of their basic and clinical pharmacology. Diabetes Ther. 2014;5:355-66.

21. Zinman B, Wanner C, Lachin JM, Fitchett D, Bluhmki E, Hantel S, Mattheus M, Devins T, Johansen OE, Woerle HJ, Broedl UC, Inzucchi SE, EMPA-REG OUTCOME Investigators. Empagliflozin, cardiovascular outcomes, and mortality in type 2 diabetes. N Engl J Med. 2015;373:2117-28.

22. Neal B, Perkovic V, Mahaffey KW, de Zeeuw D, Fulcher G, Erondu N, Shaw W, Law G, Desai M, Matthews DR, CANVAS Program Collaborative Group Canagliflozin and cardiovascular and renal events in type 2 diabetes. N Engl J Med. 2017;377:644-57.

23. Zheng SL, Roddick AJ, Aghar-Jaffar R, Shun-Shin MJ, Francis D, Oliver N, Meeran K. Association between use of sodium-glucose cotransporter 2 inhibitors, glucagon-like peptide 1 agonists, and dipeptidyl peptidase 4 inhibitors with all-cause mortality in patients with type 2 diabetes: a systematic review and meta-analysis. JAMA. 2018;319:1580-91.

24. Raz I, Mosenzon O, Bonaca MP, Cahn A, Kato ET, Silverman MG, Bhatt DL, Leiter LA, McGuire DK, Wilding JPH, Gause-Nilsson IAM, Langkilde AM, Johansson PA, Sabatine MS, Wiviott SD. DECLARE-TIMI 58: participants' baseline characteristics. Diabetes Obes Metab. 2018;20:1102-10.

25. Shigiyama F, Kumashiro N, Miyagi M, Ikehara K, Kanda E, Uchino H, Hirose T. Effectiveness of dapagliflozin on vascular endothelial function and glycemic control in patients with early-stage type 2 diabetes mellitus: DEFENCE study. Cardiovasc Diabetol. 2017;16:84.

26. White WB, Cannon CP, Heller SR, Nissen SE, Bergenstal RM, Bakris GL, Perez AT, Fleck PR, Mehta CR, Kupfer S, Wilson C, Cushman WC, Zannad F, EXAMINE Investigators. Alogliptin after acute coronary syndrome in patients with type 2 diabetes. N Engl J Med. 2013;369:1327-35.

27. Scirica BM, Bhatt DL, Braunwald E, Steg PG, Davidson J, Hirshberg B, Ohman P, Frederich R, Wiviott SD, Hoffman EB, Cavender MA, Udell JA, Desai NR, Mosenzon O, McGuire DK, Ray KK, Leiter LA, Raz I, SAVOR-TIMI 53 Steering Committee and Investigators. Saxagliptin and cardiovascular outcomes in patients with type 2 diabetes mellitus. N Engl J Med. 2013;369:1317-26.

28. Green JB, Bethel MA, Armstrong PW, Buse JB, Engel SS, Garg J, Josse R, Kaufman KD, Koglin J, Korn S, Lachin JM, McGuire DK, Pencina MJ, Standl E, Stein PP, Suryawanshi S, Van de Werf F, Peterson ED, Holman RR, TECOS Study Group. Effect of sitagliptin on cardiovascular outcomes in type 2 diabetes. N Engl J Med. 2015;373:232-42.

29. Yang TY, Liaw YP, Huang JY, Chang HR, Chang KW, Ueng KC. Association of sitagliptin with cardiovascular outcome in diabetic patients: a nationwide cohort study. Acta Diabetol. 2016;53:461-8.

30. Shigiyama F, Kumashiro N, Miyagi M, Iga R, Kobayashi Y, Kanda E, Uchino $H$, Hirose T. Linagliptin improves endothelial function in patients with type 2 diabetes: a randomized study of linagliptin effectiveness on endothelial function. J Diabetes Invest. 2017:8:330-40.

31. Bolinder J, Antuna R, Geelhoed-Duijvestijn P, Kroger J, Weitgasser R. Novel glucose-sensing technology and hypoglycaemia in type 1 diabetes: a multicentre, non-masked, randomised controlled trial. Lancet. 2016;388:2254-63.

32. UK Prospective Diabetes Study (UKPDS) Group. Effect of intensive bloodglucose control with metformin on complications in overweight patients with type 2 diabetes (UKPDS 34). Lancet. 1998:352:854-65.

33. Action to Control Cardiovascular Risk in Diabetes Study Group, Gerstein HC, Miller ME, Byington RP, Goff DC Jr, Bigger JT, Buse JB, Cushman WC, Genuth S, Ismail-Beigi F, Grimm RH Jr, Probstfield JL, Simons-Morton DG, Friedewald WT. Effects of intensive glucose lowering in type 2 diabetes. N Engl J Med. 2008;358:2545-59.

34. ADVANCE Collaborative Group, Patel A, MacMahon S, Chalmers J, Neal B, Billot L, Woodward M, Marre M, Cooper M, Glasziou P, Grobbee D, Hamet P, Harrap S, Heller S, Liu L, Mancia G, Mogensen CE, Pan C, Poulter N, Rodgers A, Williams B, Bompoint S, de Galan BE, Joshi R, Travert F. Intensive blood glucose control and vascular outcomes in patients with type 2 diabetes. N Engl J Med. 2008;358:2560-72.

35. Duckworth W, Abraira C, Moritz T, Reda D, Emanuele N, Reaven PD, Zieve FJ, Marks J, Davis SN, Hayward R, Warren SR, Goldman S, McCarren M, Vitek ME, Henderson WG, Huang GD, VADT Investigators. Glucose control and vascular complications in veterans with type 2 diabetes. N Engl J Med. 2009:360:129-39.

36. Bonds DE, Miller ME, Bergenstal RM, Buse JB, Byington RP, Cutler JA, Dudl RJ, Ismail-Beigi F, Kimel AR, Hoogwerf B, Horowitz KR, Savage PJ, Seaquist ER, Simmons DL, Sivitz WI, Speril-Hillen JM, Sweeney ME. The association between symptomatic, severe hypoglycaemia and mortality in type 2 diabetes: retrospective epidemiological analysis of the ACCORD study. BMJ 2010:340:b4909.

37. Ray KK, Seshasai SR, Wijesuriya S, Sivakumaran R, Nethercott S, Preiss D, Erqou S, Sattar N. Effect of intensive control of glucose on cardiovascular outcomes and death in patients with diabetes mellitus: a meta-analysis of randomised controlled trials. Lancet. 2009;373:1765-72.

38. Zinman B, Schmidt WE, Moses A, Lund N, Gough S. Achieving a clinically relevant composite outcome of an $\mathrm{HbA} 1 \mathrm{c}$ of $<7 \%$ without weight gain or hypoglycaemia in type 2 diabetes: a meta-analysis of the liraglutide clinical trial programme. Diabetes Obes Metab. 2012;14:77-82.

39. Einarson TR, Garg M, Kaur V, Hemels ME. Composite endpoints in trials of type-2 diabetes. Diabetes Obes Metab. 2014;16:492-9.

40. Unnikrishnan AG, Bhattacharyya A, Baruah MP, Sinha B, Dharmalingam M, Rao PV. Importance of achieving the composite endpoints in diabetes. Indian J Endocrinol Metab. 2013;17:835-43.

41. Wilkinson L, Hunt B, Johansen P, lyer NN, Dang-Tan T, Pollock RF. Cost of achieving $\mathrm{HbA1C}$ treatment targets and weight loss responses with once-weekly semaglutide versus dulaglutide in the United States. Diabetes Ther. 2018. https://doi.org/10.1007/s13300-018-0402-8. 
42. Cannon CP. Clinical perspectives on the use of composite endpoints. Control Clin Trials. 1997;18:517-29.

43. Tong BC, Huber JC, Ascheim DD, Puskas JD, Ferguson TB Jr, Blackstone EH, Smith PK. Weighting composite endpoints in clinical trials: essential evidence for the heart team. Ann Thorac Surg. 2012;94:1908-13.

44. Diabetes Control and Complications Trial Research Group, Nathan DM, Genuth S, Lachin J, Cleary P, Crofford O, Davis M, Rand L, Siebert C. The effect of intensive treatment of diabetes on the development and progression of long-term complications in insulin-dependent diabetes mellitus. N Engl J Med. 1993;329:977-86.

45. Ohkubo Y, Kishikawa H, Araki E, Miyata T, Isami S, Motoyoshi S, Kojima Y, Furuyoshi N, Shichiri M. Intensive insulin therapy prevents the progression of diabetic microvascular complications in Japanese patients with non-insulin-dependent diabetes mellitus: a randomized prospective 6-year study. Diabetes Res Clin Pract. 1995;28:103-17.

46. Introduction: standards of medical care in diabetes-2018. Diabetes Care 2018;41(Suppl 1):S1-S2. https://doi.org/10.2337/dc18-Sint01.

47. Mathieu C, Ranetti AE, Li D, Ekholm E, Cook W, Hirshberg B, Chen H, Hansen L, lqbal N. Randomized, double-blind, phase 3 trial of triple therapy with dapagliflozin add-on to saxagliptin plus metformin in type 2 diabetes. Diabetes Care. 2015;38:2009-17.

48. Cefalu WT, Leiter LA, Yoon KH, Arias P, Niskanen L, Xie J, Balis DA Canovatchel W, Meininger G. Efficacy and safety of canagliflozin versus glimepiride in patients with type 2 diabetes inadequately controlled with metformin (CANTATA-SU): 52 week results from a randomised, doubleblind, phase 3 non-inferiority trial. Lancet. 2013;382:941-50.

49. Knowler WC, Barrett-Connor E, Fowler SE, Hamman RF, Lachin JM, Walker EA, Nathan DM, Diabetes Prevention Program Research Group. Reduction in the incidence of type 2 diabetes with lifestyle intervention or metformin. N Engl J Med. 2002;346:393-403.

50. The Look AHEAD Research Group. Association of the magnitude of weight loss and changes in physical fitness with long-term cardiovascular disease outcomes in overweight or obese people with type 2 diabetes: a post hoc analysis of the Look AHEAD randomised clinical trial. Lancet Diabetes Endocrinol. 2016;4:913-21.

51. Wing RR, Lang W, Wadden TA, Safford M, Knowler WC, Bertoni AG, Hill JO, Brancati FL, Peters A, Wagenknecht L. Benefits of modest weight loss in improving cardiovascular risk factors in overweight and obese individuals with type 2 diabetes. Diabetes Care. 2011;34:1481-6.

52. American Diabetes Association. Lifestyle management: standards of medical care in diabetes-2018. Diabetes Care. 2018:41:S38-50.

53. Franz MJ, Boucher JL, Rutten-Ramos S, VanWormer JJ. Lifestyle weightloss intervention outcomes in overweight and obese adults with type 2 diabetes: a systematic review and meta-analysis of randomized clinical trials. J Acad Nutr Diet. 2015;115:1447-63.

54. Muramoto A, Matsushita M, Kato A, Yamamoto N, Koike G, Nakamura M, Numata T, Tamakoshi A, Tsushita K. Three percent weight reduction is the minimum requirement to improve health hazards in obese and overweight people in Japan. Obes Res Clin Pract. 2014;8:e466-75.

55. Nordin C. The case for hypoglycaemia as a proarrhythmic event: basic and clinical evidence. Diabetologia. 2010;53:1552-61.

56. Wright RJ, Frier BM. Vascular disease and diabetes: is hypoglycaemia an aggravating factor? Diabetes Metab Res Rev. 2008;24:353-63.

57. Cryer PE. Mechanisms of hypoglycemia-associated autonomic failure in diabetes. N Engl J Med. 2013;369:362-72.

58. Adler GK, Bonyhay I, Failing H, Waring E, Dotson S, Freeman R. Antecedent hypoglycemia impairs autonomic cardiovascular function: implications for rigorous glycemic control. Diabetes. 2009;58:360-6.

59. International Hypoglycaemia Study Group. Glucose concentrations of less than $3.0 \mathrm{mmol} / \mathrm{L}(54 \mathrm{mg} / \mathrm{dL})$ should be reported in clinical trials: a joint position statement of the American Diabetes Association and the European Association for the Study of Diabetes. Diabetes Care. 2017:40:155-7.
Ready to submit your research? Choose BMC and benefit from:

- fast, convenient online submission

- thorough peer review by experienced researchers in your field

- rapid publication on acceptance

- support for research data, including large and complex data types

- gold Open Access which fosters wider collaboration and increased citations

- maximum visibility for your research: over 100M website views per year

At BMC, research is always in progress.

Learn more biomedcentral.com/submissions 